\title{
China e India, Nuevas Oportunidades y Desafíos para América Latina y el Caribe
}

\author{
Martín Lorieto*
}

Resumen: El siguiente artículo es un análisis de la importancia comercial que reviste China e India para América Latina y el Caribe (ALC). En la primera parte se puntualizan los principales rasgos comerciales y económicos de China e India en el escenario mundial mediante el manejo de ciertos datos. En la segunda parte se describe la composición de los intercambios comerciales entre ambas regiones, aunque se realiza una distinción entre los flujos con Sudamérica y con Centroamérica para observar los patrones de comercio y de que manera los intereses principalmente de China varían en ambas regiones. Aunque se hace hincapié en las oportunidades que se pueden desprender de la mejora de las relaciones comerciales en cantidad y calidad también se identifican en una tercera parte los riesgos asociados que aparecen cuando ALC se aproxima a China e India. Finalmente se plantean las conclusiones.

Palabras-clave: Proyección Internacional, Relaciones Comerciales Internacionales, China e India, América Latina y Caribe.

Abstract: The following article is a brief study about the current commercial importance that China and India represent to Latin America and Caribbean (LAC). Firstly, the main external economic and commercial characteristics of China and India are exposed through certain data analysis. Secondly, the article describes the composition of the commercial exchanges between both regions. Although it makes a distinction between the commercial flow with South America and with Central America. Such division is done in order to visualize how trading patterns and Chinese interests change in both areas. In the third part, the article emphasizes the opportunities coming from the improvement of trading relationships in quantity as in quality. Also it identifies the associated risks that appear when LAC gets closer to China and India. Finally, the conclusions are presented to the analyzed issue.

Keywords: International Projection, International Trading Relationships, China and India, Latin America and Caribbean.

* Maestrando en Relaciones Internacionales por la Universidad de la República (Uruguay). Graduado en Estudios Internacionales por la Universidad ORT - Uruguay. E-mail: mlorieto@yahoo.com. Recebido em 06/08/06 e aceito em 01/11/07. 


\section{Introducción}

El siguiente artículo es un análisis de la importancia comercial que reviste China e India para América Latina y el Caribe (ALC). Considerando la situación de gran crecimiento por la cual atraviesan estas dos potencias emergentes en la zona asiática y su peso gravitatorio que ejercen en la economía mundial, resulta oportuno reflexionar sobre la inserción comercial que viene desarrollando ALC en ambos países. Se pondrá énfasis en la manera en que se puede perfeccionar la misma, a los efectos de que la región se beneficie de unos mejores términos de intercambio, de una inserción estable, dinámica y duradera en el tiempo mientras estas economías adquieren un mayor rol protagónico en las relaciones comerciales y económicas mundiales. En este contexto favorable, donde las relaciones comerciales y económicas de China e India se intensifican con el exterior, se torna de vital interés mejorar y fortalecer la inserción comercial. Esto se podrá realizar en la medida que la región impulse una participación activa ofreciendo una canasta exportadora diversificada y con valor agregado, orientando la misma a lograr una complementariedad y especialización productiva según las necesidades de ambos mercados.

Desde el año 2001 China e India contribuyen anualmente con más del $30 \%$ del crecimiento del producto mundial y es de esperar que sigan siendo el polo más grande de crecimiento global en los próximos años. Dos factores desempeñan un papel decisivo para impulsar esta expansión comercial y económica. Ellos son la visión estratégica y la vocación de liderazgo con las que cuentan las clases dirigentes de ambos países. Tanto China como India comparten similares visiones sobre el sistema internacional y los equilibrios mundiales de poder, de esta manera aspiran a formar parte del liderazgo global y regular la gobernabilidad internacional en las próximas décadas (CESARÍN, 2005, p. 3). Para ello, ambos países tuvieron que emprender reformas internas para contar con un rol más desequilibrante en el futuro de la región. China actualmente es un actor que combina, por un lado, una economía de mercado cada vez más abierta apostando firmemente a captar Inversión Extranjera Directa (IED), transferencia de tecnología e inversiones en infraestructura. Por otro lado, lleva adelante cambios políticos pero controlados. Se ha impulsado una transición pautada con 
una clara y fuerte actuación del Estado y un lobby diplomático cada vez más poderoso, dispuesto a actuar para generar un poder desequilibrante y con fuerza gravitatoria en la región (LÓPEZ-ALVEZ, 2002, p. 134). En el caso de India la reforma económica es más joven, poniendo énfasis en el desarrollo de una clase empresarial nacional y en el fortalecimiento de un sistema regulatorio que permita la libre competencia en ciertos sectores, en tanto que el gobierno mantiene el monopolio sobre los sectores considerados bienes públicos. Pese a ello, paulatinamente, el gobierno ha ido liberalizando estas restricciones permitiendo una mayor participación de capital extranjero en algunos sectores que antes se reservaban para los nacionales (ROSALES, KUWAYAMA, 2007, p. 10). Sin embargo, aparecen ciertos obstáculos como son las carencias de recursos en sus amplios territorios. A pesar de las compras que realizan en el exterior, India y China enfrentan periódicas crisis energéticas, por lo tanto el acceso a fuentes convencionales y alternativas es crucial para garantizar la sustentabilidad de sus respectivas estrategias de desarrollo y de liderazgo (CESARÍN, 2005, p. 10).

Teniendo en cuenta el potencial que ofrecen estos mercados para la región, en una primera parte se creyó oportuno identificar los principales rasgos comerciales y económicos de China e India mediante el manejo de ciertos datos. En una segunda parte se describe la composición de los intercambios comerciales entre ALC y ambos países, aunque se realiza una distinción entre los flujos con Sudamérica y con Centroamérica para observar los patrones de comercio y de que manera los intereses principalmente de China varían en ambas regiones. Aunque se hace hincapié en las oportunidades que se pueden desprender de la mejora de las relaciones comerciales en cantidad y calidad también se identifican en una tercera parte los riesgos comerciales asociados, como son las amenazas, debilidades y desafíos, con los que se enfrenta ALC cuando se aproxima a China e India. Finalmente, a modo de conclusión es oportuno reflexionar sobre la visión estratégica de inserción que debería asumir la región para obtener el máximo beneficio de su relación con estas dos potencias emergentes ya que progresivamente vienen aumentando su demanda de recursos naturales para mantener sus altas tasas de crecimiento y abriendo gradualmente sus mercados a la competencia exterior. 


\section{Principales características comerciales y económicas de China e India}

Si se pasa a evaluar el desempeño de ambas economías, en China el dinamismo de la inversión interna y las exportaciones le permitieron crecer aproximadamente un $10 \%$ en 2005, ratificando el promedio próximo a los dos dígitos en las últimas tres décadas. India exhibió un crecimiento no menos significativo del $8,4 \%$, con una expansión del consumo interno de un $8 \%$. En 2005, el sector manufacturero indio creció un 9,0\%. Los textiles y los metales básicos y sus aleaciones, así como los equipos de transporte fueron los rubros más dinámicos. Por su parte, el sector agrícola creció solo un $2,3 \%$ en 2005 , debido a la baja productividad que sufre dicho sector. Se proyecta que mantendrá ese ritmo de crecimiento en los próximos años, en tanto el sector de servicios seguirá como motor de desarrollo económico, creciendo un $10 \%$ por año (CEPAL, 2006, p. 42).

El peso de China en el comercio mundial supera ampliamente al de India. En el 2005 se mantuvo el auge de exportaciones de mercancías chinas, fenómeno que se ha ido acentuando desde el inicio de la presente década. Las exportaciones para dicho año crecieron un $28 \%$ y alcanzaron los 762.000 millones de dólares, cifra que representó el 7,5\% de las exportaciones mundiales de bienes. Las importaciones aumentaron a un ritmo del $18 \%$ y llegaron a los 660.000 millones de dólares, cifra que correspondió al 6,3\% de las importaciones mundiales. En el 2005 China pasó a ser la tercera potencia importadora y exportadora de mercancías del comercio mundial, con lo cual se amplió aún más su superávit comercial (CEPAL, 2006, p. 43). El papel de India en el comercio es mucho menor. En 2005 sus exportaciones e importaciones de mercancías totalizaron 89.800 millones de dólares y 131.600 millones de dólares, respectivamente. Estas cifras se explican en parte debido a que India cuenta con una apertura comercial más reducida y controlada que China. Mientras esta última presenta una estructura arancelaria mucho menor y lineal, la de India contiene elevados niveles de protección, sobre todo en el sector agrícola (CEPAL, 2006, p. 43).

En los últimos años China e India han negociado un variado número de acuerdos comerciales. Actualmente China negocia con 28 países y regiones acuerdos de libre comercio destacándose el área de libre comercio con Chile 
y el acuerdo sobre mercancías con la Asociación de Naciones del Sureste Asiático (ASEAN) ${ }^{1}$. Por su parte India ha celebrado 13 acuerdos de libre comercio, y está negociando acuerdos con otros tres grupos de países y estudia la posibilidad de llegar a formalizar acuerdos con otros ocho países (CEPAL, 2006, p. 51).

\section{Intercambios comerciales y económicos de ALC con China e India}

Los intercambios comerciales de la región con China e India para el periodo 1990 - 2005 aumentaron notablemente. En la Tabla 1 se aprecia la importancia que encierra China como socio comercial para ALC. Las exportaciones de la región a China superaron los 19.000 millones de dólares en 2005, (cifra que representa cerca del 3,5\% de las exportaciones totales de la región), mientras que las exportaciones dirigidas a India solo ascendieron a los 3.000 millones de dólares, (cifra que equivale a una participación muy reducida del 0,5\% en los totales regionales). Brasil, Chile, Argentina, Perú y México (por orden de importancia en 2005) son los principales países de ALC que exportan hacia China. En el caso de India, además de los anteriores países señalados, aparece Perú. (CEPAL, 2006, p. 45)

\footnotetext{
${ }^{1}$ Brunei, Camboya, Filipinas, Indonesia, Laos, Malasia, Myanmar, Singapur, Tailandia y Vietnam.
} 
Tabla 1 - ALC: Exportaciones hacia China e India, 20052

(En millones de US\$ y porcentajes del total)

\begin{tabular}{|l|c|c|c|c|c|c|c|}
\hline Origen & \multicolumn{3}{|c|}{$\begin{array}{c}\text { Exportaciones totales según } \\
\text { destino }\end{array}$} & \multicolumn{2}{c|}{$\begin{array}{c}\text { Participación de } \\
\text { países en el total de } \\
\text { exportaciones de ALC }\end{array}$} & $\begin{array}{c}\text { \% del total de cada } \\
\text { país }\end{array}$ \\
\hline ALC & India & China & Mundo & India & China & India & China \\
\hline Brasil & 3.048 & 19.442 & 555.445 & 100 & 100 & 0,5 & 3,5 \\
\hline Chile & 1.137 & 6.834 & 118.308 & 37,3 & 35,2 & 1,0 & 5,8 \\
\hline Argentina & 493 & 4.390 & 39.536 & 16,2 & 22,6 & 1,2 & 11,1 \\
\hline México & 729 & 3.302 & 40.013 & 23,9 & 17,0 & 1,8 & 8,3 \\
\hline Perú & $\mathbf{5 2 2}$ & 1.091 & 213.711 & 17,1 & 5,6 & 0,2 & 0,5 \\
\hline
\end{tabular}

FUENTE: CEPAL. Sobre la base de información oficial de los países y datos del Fondo Monetario Internacional, Direction of Trade Statistics, 2006

En la tabla anterior, al observar los valores se aprecia que México y Brasil son los países de ALC que cuentan con mayor valor en las exportaciones hacia el mundo en general con US\$213.771 y US\$118.308 respectivamente para el año 2005. Pese a ello, llama la atención el reducido valor de las exportaciones mexicanas hacia China con tan solo US\$1.091 por debajo de las exportaciones peruanas de US\$ 1.826. En el caso brasilero, con menor valor en las exportaciones hacia el mundo comparado con México, presenta un valor mucho más elevado en el mercado chino con US\$ 6.834, encabezando así el grupo de los principales países exportadores de la región hacia China y también hacia la India. Asimismo, se destaca la participación cada vez mayor de Chile con US\$ 4.390 y Argentina con US\$ 3.302. Al observar la segunda columna Brasil es el que tiene mayor porcentaje de participación en las exportaciones de ALC hacia ambas economías, con alrededor de un $35 \%$, le sigue Chile y luego Argentina. En la última columna se aprecia a Chile con el mayor porcentaje de participación con un $11,1 \%$ en el mercado chino en relación con el total de sus exportaciones hacia el mundo. Le sigue Argentina

\footnotetext{
${ }^{2}$ La Tabla 1 muestra en tres diferentes columnas los valores expresados en millones de dólares estadounidenses y los porcentajes de participación de las exportaciones totales de ALC y de los principales países exportadores de la región hacia China e India. En la primera columna aparecen los valores de las exportaciones totales de ALC hacia ambos mercados y el resto del mundo. Idéntica exposición se realiza con los cinco países seleccionados. En la segunda columna se muestra los porcentajes de participación que le corresponden a cada país en las exportaciones totales de ALC hacia ambos mercados. Por último, en la tercera columna se puede apreciar los porcentajes de participación que tiene China e India en las exportaciones totales de ALC y de cada país.
} 
con $8,3 \%$ y Brasil con 5,8\%. Si se hace el mismo ejercicio con India se tiene que los porcentajes son muy reducidos en general. Argentina y Chile son los que tienen mayor participación en el mercado indio en relación con el total de sus exportaciones hacia el mundo con un 1,8\% y 1,2\% respectivamente. Los valores que se expusieron al inicio y estos porcentajes de participación dejan entrever que la importancia de India como destino de las exportaciones para los países de ALC aún es muy reducida y en algunos casos como México y Perú casi insignificante.

Si se pasa a observar la composición de los intercambios entre China y ALC se distingue una clara diferencia entre lo que ALC le vende y lo que le compra. Mientras la primera región se concentra en materias primas intensas en recursos naturales, China se enfoca en la exportación de bienes con alto nivel tecnológico e industrial. Los productos importados por ALC desde China son ampliamente variados. La mayor cantidad corresponde a computadoras y sus unidades, equipos eléctricos y electrónicos como aire acondicionados, radios, videograbadoras, etc. En países en los cuales se llevan a cabo producciones (montaje, armado) de electrodomésticos como México y Brasil, han aumentado las importaciones de partes y componentes electrónicos relacionados entre otros a la imagen y transmisión (JETRO, 2005, p. 5). En la Tabla 2 se observan las principales categorías de importaciones provenientes de china en porcentajes para 2003. Un 56\% corresponde a maquinarias y equipos electrónicos de alto nivel tecnológico, inmediatamente después están las manufacturas con un $32 \%$ sobresaliendo las manufacturas de transportes, mecánicas y plásticas. La tendencia de China durante algunas décadas consistió en generar exportaciones de bienes que tuviesen niveles de intensidad bajos y medios de tecnología en donde podían competir cómodamente frente a otras regiones. Aunque, dichas exportaciones tienen un peso importante en la canasta exportadora, se incrementaron notoriamente las exportaciones de bienes que incorporan una mayor intensidad tecnológica. 
Tabla 2 - Principales categorias de importaciones de ALC provenientes de China, 2003 (Porcentajes del total)

\begin{tabular}{|l|c|}
\hline Maquinarias y equipos & $56 \%$ \\
\hline Manufacturas Gral. & $32 \%$ \\
\hline Químicos & $7 \%$ \\
\hline Combustibles yLubricantes & $3 \%$ \\
\hline Otros & $2 \%$ \\
\hline Total & $100 \%$ \\
\hline
\end{tabular}

FUENTE: Cooperación Andina de Fomento (CAF), Reporte de Economía y Desarrollo, 2005

Para el caso de las exportaciones totales de ALC hacia china en el 2004, en la Tabla 3 se tiene que los metales encabezan la principal categoría de exportación con un $40 \%$, entre ellos están el cobre y el hierro. Siguen los alimentos destacándose la soja y las frutas oleaginosas, aunque bastante más retrasados con un $20 \%$. En una posición mas relegada están los aceites en general con casi un $13 \%$. Las maquinarias y equipos aparecen con una participación muy reducida con cerca de un $2 \%$.

Tabla 3 - Principales categorias de exportaciones de ALC hacia China, 2004

(Porcentajes del total)

\begin{tabular}{|l|c|}
\hline Metales & $40 \%$ \\
\hline Alimentos & $20 \%$ \\
\hline Aceites & $12,7 \%$ \\
\hline Papeles y derivados & $4,5 \%$ \\
\hline Piensos & $4 \%$ \\
\hline Cueros & $3 \%$ \\
\hline Maquinarias y equipos & $1,8 \%$ \\
\hline Madera & $1,2 \%$ \\
\hline Total & $100 \%$ \\
\hline
\end{tabular}

FUENTE: Cooperación Andina de Fomento (CAF), Reporte de Economía y Desarrollo, 2005

Se constata que la región representa para China un área proveedora de materias primas con gran dotación de recursos naturales. Como se vino explicando, la demanda por materias primas es notorio en el caso chino. Entre ellas esta la soja, que en el correr de una década alcanzó porcentajes extremadamente elevados, poniendo en evidencia la necesidad de estas potencias emergentes no solo de importar recursos energéticos para la 
industria, sino también de alimentos para sostener el crecimiento de la población.

Si se observa la canasta exportadora de India hacia ALC también es concentrada como se aprecia en la Tabla 4. Las principales categorías de exportación concentran casi un $60 \%$ del total de las exportaciones hacia ALC. A diferencia de China, la India tiene un rubro muy importante como son los combustibles, dentro del mismo el petróleo es el producto mas destacado. Luego, aparecen los fármacos como son los medicamentos y los antibióticos. En tercer lugar se encuentran los vehículos, mediante la presencia de automóviles y motocicletas. Inmediatamente después se ubican los químicos, los cuales han experimentado un rápido crecimiento con respecto al periodo $2004-2005$.

Tabla 4 - Principales categorias de exportacion de India hacia ALC, 2005-2006

(Porcentajes del total)

\begin{tabular}{l|c} 
Combustibles & $45.5 \%$ \\
\hline Fármacos & $12 \%$ \\
\hline Vehículos en Gral. & $11,5 \%$ \\
\hline Químicos & $9,5 \%$ \\
\hline Vestimenta y textiles & $8,0 \%$ \\
\hline Maquinarias, equipos y repuestos & $6 \%$ \\
\hline Otros & $7,5 \%$ \\
\hline Total $^{* 4}$ & $100 \%$
\end{tabular}

FUENTE: Gobierno de India, Ministerio de Industria y Comercio; Departamento de comercio, http://dgft.delhi.nic.in/

En las exportaciones de ALC hacia India se puede apreciar una similitud con el caso chino. La canasta exportadora se encuentra muy poco diversificada. Como se muestra en la Tabla 5 las principales categorías de exportación hacia ese mercado representan alrededor de un $77 \%$ del total de las exportaciones durante el ańo fiscal 2005 - 2006. Como se observa en la Tabla hay una gran concentración de productos primarios y manufacturas basadas en recursos naturales. Es muy destacada la participación de los alimentos principalmente mediante la presencia de la soja como en el caso chino. El rubro metales aparece en segunda posición, destacándose fuertemente el cobre y sus concentrados, aunque también aparece el hierro con sus derivados pero con

\footnotetext{
${ }^{3}$ Este $100 \%$ representa el 59,8 \% del total de las exportaciones de India hacia ALC.
} 
una participación mucho menor. El rubro vehicular aparece en una tercera posición sobresaliendo la industria de los astilleros que ha experimentado un considerable crecimiento con respecto al periodo 2004 -2005 a través de embarcaciones ligeras y cruceros. Inmediatamente después están situados los combustibles destinados para el proceso de industrialización.

Tabla 5 - Principales categorias de exportación de ALC hacia india, 2005-2006

(Porcentajes del total)

\begin{tabular}{l|c}
\hline Alimentos & $47,3 \%$ \\
\hline Metales & $24,5 \%$ \\
\hline Vehículos en Gral. & $14 \%$ \\
\hline Combustibles & $6,5 \%$ \\
\hline Maquinarias, equipos y repuestos & $3 \%$ \\
\hline Madera en bruto & $2 \%$ \\
\hline Cueros y pieles & 1,3 \\
\hline Químicos & $1,3 \%$ \\
\hline Total $^{* 5}$ & $100 \%$
\end{tabular}

FUENTE: Gobierno de India, Ministerio de Industria y Comercio; Departamento de Comercio, http://dgft.delhi.nic.in/

\section{Intercambios comerciales y económicos de China e India con Sudamérica y Centroamérica}

Sin embargo, los intereses comerciales de China en ALC varían según se trate de América del Sur, por una parte, y Centroamérica y México, por otra. En los intereses de China en América del Sur intervienen varios factores. Primero, para su rápido crecimiento China necesita asegurar el acceso y abastecimiento de materias primas, alimentos y productos energéticos. Segundo, busca un escenario de mercado favorable para sus exportaciones y limitar las acusaciones de defensa comercial como las de antidumping (CEPAL, 2006, p. 46).

Varios países de la región, dejan en claro que China es uno de los principales mercados para sus exportaciones. El comercio de los países de América del Sur ha sido muy favorable. La subregión acumula un superávit creciente por cuatro ańos consecutivos hasta 2005. Sin embargo, si se observa con cautela en la Tabla 6 el superávit acumulado se concentra en los productos primarios

\footnotetext{
${ }^{4}$ Este $100 \%$ representa el 77, $2 \%$ del total de las exportaciones de ALC hacia India.
} 
y las manufacturas basadas en recursos naturales, mientras que se incrementó el déficit en manufacturas que incorporan tecnología (CEPAL, 2006, 46).

Tabla 6 - América del sur: intercambios comerciales con China según intensidad tecnológica, 1990-1994 y 2000-2004*

(en millones de dólares corrientes)

\begin{tabular}{|c|c|c|c|c|c|c|}
\hline \multirow{2}{*}{ Sectores } & \multicolumn{2}{|c|}{ Exportaciones } & \multicolumn{2}{|c|}{ Importaciones } & \multicolumn{2}{|c|}{ Balance Comercial } \\
\hline & $1990-1994$ & $2000-2004$ & $1990-1994$ & $2000-2004$ & $1990-1994$ & $2000-2004$ \\
\hline $\begin{array}{l}\text { Productos } \\
\text { Primarios }\end{array}$ & 446 & 2.000 & 56161 & 161 & 390 & 3.839 \\
\hline $\begin{array}{l}\text { Manuf. } \\
\text { basadas en } \\
\text { RR.NN. }\end{array}$ & 324 & 2.182 & 83 & 876 & 241 & 1306 \\
\hline $\begin{array}{c}\text { Tecnología } \\
\text { baja }\end{array}$ & 176 & 502 & 230 & 2.154 & -55 & -1653 \\
\hline $\begin{array}{l}\text { Tecnología } \\
\text { media }\end{array}$ & 213 & 601 & 154 & 1.578 & 59 & -977 \\
\hline $\begin{array}{c}\text { Tecnología } \\
\text { alta }\end{array}$ & 4 & 94 & 51 & 1.759 & -48 & -1665 \\
\hline Total & 1.162 & 7.379 & 574 & 6.529 & 587 & 850 \\
\hline
\end{tabular}

FUENTE: CEPAL, División de Comercio Internacional e Integración sobre la base de información oficial de la base de datos COMTRADE de Naciones Unidas.

* Promedios anuales para los períodos indicados.

Es importante señalar que en el plano bilateral, China interactúa activamente con Brasil en el sistema internacional (Naciones Unidas), forman parte del BRIC (Brasil, Rusia, India y China), reconocidas como futuras potencias económicas. Mantiene una relación política estable con Argentina basada en principios permanentes, mientras que con Chile (primer país de ALC en reconocer el gobierno de Beijing) ha consolidado una relación intensa en términos económicos debido a la multiplicidad de instancias de negociación y consulta que la malla de acuerdos transpacíficos ofrece. Relaciones particularmente intensas en el plano político desarrolla la nueva dirigencia china con Venezuela. Otros estados latinoamericanos como Perú, Colombia y Uruguay despliegan recursos que permitan una mayor sintonía de sus respectivos procesos económicos con el auge económico chino (CESARÍN, 2005, p. 14).

Si se pasa a analizar los flujos de comercio de Centroamérica y México con China se puede apreciar una asimetría en sus intercambios principalmente en la balanza comercial y no tanto en la composición de los intercambios 
como ocurre con Sudamérica ya que sus exportaciones no se encuentran tan concentradas en productos primarios. Como muestra la Tabla 7, tal asimetría se refleja en el hecho de que los principales productos que dominan las importaciones de China desde México y Centroamérica son manufacturas, sobre todo del sector electrónico, con la excepción del cobre y el mineral de hierro (CEPAL, 2006, p. 47). Esto permite entrever que existe una cierta competencia entre México y China en ciertos rubros como son las manufacturas del sector electrónico. El saldo hasta el momento no ha sido favorable para México, debido a que compite directamente con la producción china, y además la cuota de cada producto en el mercado chino es todavía muy reducida. Dicha competencia se traslada también al interior del mercado mexicano que ha sido inundado por productos chinos desequilibrando la balanza comercial negativamente. Se destacan las importaciones de televisores, filmadoras, equipos de transmisión, computadoras, juguetes, entre otros productos que México también produce. En consecuencia, México al igual que Centroamérica acumula un déficit comercial creciente con China (CEPAL, 2006, p. 47).

Tabla 7 - México: intercambios comerciales con China según intensidad tecnológica, 1990-1994 Y 2000-2004 *

(en millones de dólares corrientes)

\begin{tabular}{|c|c|c|c|c|c|c|}
\hline \multirow{2}{*}{ Sectores } & \multicolumn{2}{|c|}{ Exportaciones } & \multicolumn{2}{|c|}{ Importaciones } & \multicolumn{2}{|c|}{ Balance Comercial } \\
\hline & $1990-1994$ & $2000-2004$ & $1990-1994$ & $2000-2004$ & $1990-1994$ & $2000-2004$ \\
\hline $\begin{array}{l}\text { Productos } \\
\text { Primarios }\end{array}$ & 4 & 19 & 9 & 108 & -5 & -88 \\
\hline $\begin{array}{c}\text { Manuf. } \\
\text { basadas en } \\
\text { RR.NN. }\end{array}$ & 5 & 22 & 24 & 388 & -19 & -366 \\
\hline $\begin{array}{c}\text { Tecnología } \\
\text { baja }\end{array}$ & 3 & 12 & 131 & 1.392 & -128 & -1.380 \\
\hline $\begin{array}{c}\text { Tecnología } \\
\text { media }\end{array}$ & 47 & 71 & 106 & 1.667 & -59 & -1.596 \\
\hline $\begin{array}{c}\text { Tecnología } \\
\text { alta }\end{array}$ & 2 & 253 & 73 & 3.660 & -71 & -3.407 \\
\hline Total & 61 & 378 & 344 & 7.214 & -282 & -6.836 \\
\hline
\end{tabular}

FUENTE: CEPAL, División de Comercio Internacional e Integración sobre la base de información oficial de la base de datos COMTRADE de Naciones Unidas.

${ }^{*}$ Promedio anuales para los períodos indicados. 
Considerando lo anterior, y pasando al plano del relacionamiento bilateral la relación mantenida entre China y México no resulta sencilla. Fue el último país con el que China negoció su ingreso a la Organización Mundial del Comercio (OMC) debido a que varios sectores mexicanos mantuvieron una postura muy crítica ya que perciben a China como una amenaza real que ha desplazado su producción local en el mercado estadounidense como socio principal y ha ocasionado la salida de inversiones localizadas en maquilas (CESARIN, 2005, p. 14). A pesar de que cada grupo exporta hacia el mercado estadounidense productos de alta tecnología, estimados en unos 40.000 millones de dólares, la mayor competencia entre ambos se concentra en las manufacturas de intensidad tecnológica baja y media. Este hecho se observa claramente en el sector textil y de confecciones, donde tanto México como Centroamérica han perdido una cuota importante del mercado. Lo mismo ocurre, con creces, en el sector eléctrico y electrónico, especialmente los equipos de computación (CEPAL, 2006, p. 47). Es evidente que existe una competencia por parte de china muy fuerte que se apoya principalmente en sus bajos costos de producción y su gradual mejora de calidad en la producción.

El mercado de ALC aún no es muy significativo para India, aunque dicha tendencia empieza a revertirse gradualmente. Las importaciones equivalen apenas a una décima parte de lo que representan las originadas en China. Sin embargo, en el último tiempo las compras de productos indios fueron aumentando. Las exportaciones hacia india son aún más reducidas, tal vez el proteccionismo que presenta la economía india es uno de los factores que explica el bajo vínculo comercial entre ambos actores. Así, en 2005 la región representó solo un 3,0\% (2.168 millones de dólares) y un 1,8\% (1.882 millones de dólares) de las exportaciones e importaciones de India respectivamente. No obstante, sus exportaciones a la región se han ido triplicando y sus importaciones se han duplicado en los últimos años (CEPAL, 2005, p. 48). México, Brasil, Argentina, Chile, Colombia y Venezuela son considerados los seis principales socios en la región. Por un lado concentran el $88 \%$ de sus exportaciones y por otro son el origen del $95 \%$ de las importaciones indias desde ALC. En manufacturas la India exporta a la región automóviles, auto partes, accesorios electrónicos, maquinaria, 
software, productos farmacéuticos, agroquímicos, plásticos, resinas y aceites esenciales. Las compras de India en la región consisten en hierro y acero, metales no ferrosos, minerales, químicos, pulpa, papel, cueros y derivados y alimentos (CESARÍN, 2005, p. 16).

Como ocurre con China, el comercio de India con América del Sur es diferente del que mantiene con Centroamérica y México. Esto se explica ya que existen tratados comerciales entre India y los países del Mercado Común del Sur (MERCOSUR) ${ }^{5}$ y Chile por los cuales se viene exportando a India aceites vegetales, minerales y sus concentrados, azúcar y miel. Asimismo, por parte de ellos se viene importando de India productos refinados del petróleo, medicamentos y productos farmacéuticos, otros productos químicos orgánicos y textiles. A diferencia de lo anterior, el comercio de India con México y Centroamérica es muy reducido. Esta subregión se concentra principalmente en la exportación de petróleo, productos farmacéuticos y equipos de telecomunicaciones e importa automóviles y piezas para automóviles, así como textiles y confecciones, rubros que parecen ofrecer una ventaja comparativa a la región (CEPAL, 2006, p. 48).

Finalmente, en cuanto a las inversiones indias en ALC, se encuentran muy lejos de los montos proyectados por China, aunque las previsiones establecidas por firmas indias sugieren el aumento de inversiones en la región. Las mismas estarían orientadas hacia el sector farmacéutico (Brasil donde ya opera Rambaxy, México, Chile y Venezuela), IT (Uruguay, México), industria química (Colombia), sector minero (Chile), agronegocios, sector forestal y servicios (Brasil y Argentina), petróleo y gas (Brasil, México, Venezuela) lideradas por grandes firmas indias estatales y privadas en busca de nuevos mercados, centros de provisión, desarrollo de redes tecnológicas y servicios (CESARÍN, 2005, p. 16).

\section{El papel de la ASEAN y ALC}

La oferta exportable de India se distingue claramente de la de China. Mientras la especialización de las exportaciones chinas se ha modificado marcadamente, la composición de las exportaciones de India no ha tenido mayores cambios durante los últimos 15 ańos. China apuesta a una

\footnotetext{
${ }^{5}$ Argentina, Brasil, Paraguay, Uruguay y Venezuela.
} 
especialización cada vez más marcada en sectores de alta tecnología y de valor agregado y ha ido abandonando gradualmente las áreas que ofrecen ventajas comparativas tradicionales como las manufacturas de baja tecnología (entre ellas, los textiles y la vestimenta). En contraposición, India no ha podido penetrar en los mercados de productos de tecnología avanzada, orientando su especialización exportadora sobre todo a los productos industriales tradicionales. En India, el comercio y la inversión extranjera directa aún no se articulan estrechamente, a diferencia de lo que ocurre en China. Esto no solo plantea dificultades para que el país logre una mayor inserción en los mercados mundiales de productos de valor agregado y de conocimiento, sino que también obstaculiza su ingreso a la dinámica red del comercio intrafirma y del comercio intraindustrial asiático (CEPAL, 2006, p. 50).

A pesar de ello, la participación de India en los flujos de comercio con las dos agrupaciones de países en desarrollo, la ASEAN y Asociación Latinoamericana de Integración (ALADI $)^{6}$, muestra una mayor integración en la red de comercio intraindustrial asiática. Como muestra la Tabla 8, los países de la ASEAN son una fuente de suministro muy importante de bienes primarios y manufacturas basadas en recursos naturales para la India, más que los países de la ALADI. Asimismo, la participación de la ASEAN en las importaciones de manufacturas de la India es relativamente alta. Casi el $16 \%$ de las importaciones de manufacturas de India de alta tecnología y casi el $8 \%$ de las manufacturas de tecnología media y baja provienen de los países vecinos integrantes de la ASEAN (CEPAL, 2006, p. 50).

${ }^{6}$ Argentina, Brasil, Bolivia, Colombia, Chile, Cuba, Ecuador, México, Paraguay, Perú, Uruguay y Venezuela. 
Tabla 8 - China e India: composición del comercio con la ASEAN y la ALADI, 2004 (En \% de participación en los flujos de comercio de cada grupo de productos)

\begin{tabular}{|c|c|c|c|c|c|}
\hline \multirow[t]{2}{*}{ Categoría } & \multirow[t]{2}{*}{ Grupo } & \multicolumn{2}{|c|}{ China } & \multicolumn{2}{|c|}{ India } \\
\hline & & Importación & Exportación & Importación & Exportación \\
\hline \multirow{2}{*}{ Primarios } & ASEAN & 9,0 & 9,9 & 16,1 & 8,4 \\
\hline & ALADI & 13,3 & 0,9 & 6,8 & 0,3 \\
\hline \multirow{2}{*}{$\begin{array}{l}\text { Manufacturas } \\
\text { basadas en } \\
\text { recursos naturales }\end{array}$} & ASEAN & 15,6 & 11,1 & 14,5 & 16,5 \\
\hline & ALADI & 7,8 & 3,4 & 3,9 & 3,1 \\
\hline \multirow{2}{*}{$\begin{array}{l}\text { Manufacturas de } \\
\text { baja tecnología }\end{array}$} & ASEAN & 5,0 & 4,1 & 8,2 & 3,4 \\
\hline & ALADI & 2,4 & 2,2 & 0,9 & 1,3 \\
\hline \multirow{2}{*}{$\begin{array}{l}\text { Manufacturas de } \\
\text { tecnología media }\end{array}$} & ASEAN & 6,2 & 8,4 & 8,3 & 11,5 \\
\hline & ALADI & 1,2 & 3,1 & 1,5 & 3,7 \\
\hline \multirow{2}{*}{$\begin{array}{l}\text { Manufacturas de } \\
\text { alta tecnología }\end{array}$} & ASEAN & 19,5 & 8,3 & 15,9 & 9,7 \\
\hline & ALADI & 0,6 & 1,7 & 0,4 & 4,4 \\
\hline \multirow{2}{*}{ Otros } & ASEAN & 4,7 & 3,2 & 2,1 & 23,8 \\
\hline & ALADI & 0,6 & 0,5 & 0,1 & 0,5 \\
\hline
\end{tabular}

FUENTE: CEPAL, sobre la base de información de la Base de datos estadísticos sobre el comercio de mercaderías (COMTRADE)

En el caso chino, se puede observar que depende más de los países de la ALADI que de los países de la ASEAN como fuente de suministro de productos primarios. Esta misma tendencia se revierte para las manufacturas basadas en recursos naturales, ya que la ASEAN duplica la participación de la ALADI en el mercado chino. Aproximadamente el 20\% de las manufacturas de alta tecnología importadas por China proviene de los países de la ASEAN, mientras que el $8 \%$ de las exportaciones chinas de productos de al ta tecnología y más del $11 \%$ de las manufacturas basadas en recursos naturales tienen como destino los países de la ASEAN. Estos porcentajes ponen en evidencia que existe una red de comercio intraindustrial entre China y la ASEAN, en donde una parte importante de las materias primas y las manufacturas basadas en recursos naturales pertenecen a sectores en los cuales los países miembros de la ALADI enfrentan una severa competencia con los países asiáticos (CEPAL, 2006, p. 50).

Aunque la especialización de ALC difiere sustancialmente con respecto a la de los países del ASEAN, esta última constituye un competidor directo para los países de la región de ALC, tanto en el ámbito de productos primarios 
como de manufacturas. Los países asiáticos han logrado transformar su canasta exportadora hacia el mercado chino, de manera muy marcada, desde fines de la década de los 90. Actualmente, el sector de alta tecnología representa casi la mitad de sus exportaciones a China, lo que contrasta notablemente con el caso latinoamericano, donde más del $70 \%$ de las exportaciones hacia esta economía emergente consiste en productos primarios y manufacturas intensivas en recursos naturales. Sin embargo, hay un aspecto a considerar y es que aún el 30\% de las exportaciones de la ASEAN hacia China corresponde a categorías en las que ALC tiene ventajas comparativas (CEPAL, 2005, p. 153).

Además, al margen de la composición del tipo de comercio que se desarrolla, si se tiene en cuenta el comercio global de China, se puede apreciar que los principales socios comerciales de China son los países vecinos de Asia y el Pacífico, especialmente Japón y los países del ASEAN. Este grupo de países proveen a China del $54 \%$ de sus importaciones y es el destino del $44 \%$ de sus exportaciones totales. Una de las razones es la realización del acuerdo de libre comercio entre China y la ASEAN firmado en noviembre del 2002 con el objeto de mejorar la cooperación económica en el comercio de bienes, servicios e inversiones. La cobertura del Acuerdo recientemente se expandió cuando la ASEAN y China firmaron el acuerdo sobre Comercio de Bienes, que implica ahorros arancelarios concretos en el comercio de productos. Este acuerdo se esta aplicando desde julio de 2005. Las preferencias arancelarias concedidas se aplicarán a las importaciones desde la ASEAN hacia China con un $10 \%$ y desde China hacia la ASEAN con un 15\% (CEPAL, 2005, p. 165).

Los porcentajes de participación dejan entrever la importancia comercial que reviste ASEAN por su cercanía geográfica y la acertada estrategia que ha decidido adoptar para mejorar sus relaciones comerciales y económicas con China.

Finalmente, es necesario advertir que la competencia que se plantea entre la producción asiática y latinoamericana en el mercado chino se podría ampliar hacia otras áreas sensibles para esta última como es el caso de la agroindustria. En China persisten antiguas estructuras agrarias corporativas en donde la industria no es dinámica y flexible, por lo cual resulta difícil que 
pueda comenzar una exportación a gran escala. Sin embargo, a pesar de ello gradualmente comienza adquirir formas más sofisticadas y corporativas que acompañadas de ciertos capitales podrían generar una industria agraria de exportación. Algunos antecedentes existen, y de hecho ciertos productos se consumen en la región asiática. Aunque exista esta posibilidad, los capitales extranjeros encuentran dificultades en esa área por lo cual se encuentran más disponibles a invertir en otros sectores donde el Estado chino esta más dispuesto a estimular el desarrollo industrial por el momento, beneficiando así a los productores de ALC (LÓPEZ-ALVES, 2002, p. 136).

\section{Estrategia de inserción: tratados de libre comercio con China e India}

China e India han negociado varios acuerdos comerciales en estos últimos años. Por el lado de China, ha firmado y está negociando acuerdos de libre comercio con por lo menos 27 países. Por su parte India también está creando una compleja red de acuerdos comerciales. Concretó 13 acuerdos de libre comercio, entre los cuales se encuentran los Acuerdos Parciales con Chile y el MERCOSUR. El logró de Chile fue relevante en este plano debido a que se convirtió en el primer país occidental con el que China firmó un Acuerdo de Alcance Parcial dirigido principalmente a los bienes en Octubre de 2005. Mediante este acuerdo se debería de aplicar un arancel cero al $92 \%$ de las actuales exportaciones de Chile hacia el mercado Chino. Con respecto a otros productos, como salmones, uvas, cerezas, duraznos y manzanas, se estipulan desgravaciones graduales que se llevarían a cabo en los 10 años posteriores a la entrada en vigor del acuerdo. Ambos países han previsto incluir otros temas además de la liberalización del comercio de mercancías. De esta manera, el tratado establece un mecanismo de solución de controversias e incorpora el tema de la cooperación en áreas como la ciencia y la tecnología, la seguridad social, la educación, la promoción de inversiones, la cultura, las pequeñas y medianas empresas (pymes), la propiedad intelectual y el medio ambiente (CEPAL, 2005, p. 51). En el Acuerdo de Alcance Parcial entre India y Chile - firmado el 8 de marzo de 2006 - se estipula que: i) el 98\% de las exportaciones chilenas y el $91 \%$ de las exportaciones indias obtendrán un promedio de rebaja arancelaria del 20\%; ii) Chile rebajará los aranceles 
de 296 productos indios, mientras que India rebajará los aranceles de 178 productos chilenos. Estas rebajas oscilan entre el 10\% y el 50\% de las tasas. Entre las exportaciones chilenas favorecidas figuran el cobre, la celulosa, los tableros de madera y los salmones, todas ellas materias primas.

Con respecto al Acuerdo de Alcance Parcial firmado entre el MERCOSUR e India hay que puntualizar su importancia dentro del marco de la cooperación Sur-Sur. Aunque el Acuerdo no reportaría beneficios comerciales inmediatos de gran alcance - el comercio recíproco representa apenas el 1\% de cada bloque -, a través del mismo India aspira a expandir sus exportaciones de rubros estratégicos, como el de los productos farmacéuticos y químicos, los equipos de transporte, los textiles y la confección, mientras que por el lado de los países del MERCOSUR gran parte de sus intereses apuntan a diversificar su canasta exportadora, compuesta principalmente por aceites vegetales (soja), concentrados de minerales ferrosos y maquinaria no eléctrica (CEPAL, 2006, p. 51).

\section{Conclusiones}

En atención a lo anteriormente expuesto, es altamente probable que los países latinoamericanos se beneficien en determinadas áreas y en otras se encuentren expuestos a una fuerte competencia por parte de estas dos economías emergentes como resultado de sus respectivos procesos de modernización en marcha como son las reformas y la apertura a las corrientes comerciales.

La configuración de las relaciones económicas externas de China e India y su proyección en ALC, reflejan sus crecientes interacciones y dependencias con el mundo en desarrollo. La inserción china y en menor medida de la India en ALC permite observar el esfuerzo por estrechar vínculos políticos y económicos en los planos bilateral, subregional, y con organizaciones regionales de cooperación a fin de garantizar el acceso a fuentes de recursos naturales, materias primas, reduciendo los espacios de maniobra política y económica de otros actores. En este contexto, podría esperarse que las relaciones entre la región y estos dos países se construyan en base a un eje de cooperación a largo plazo.

La necesidad por el suministro de materia prima ha llevado a que China 
pasara a ocupar la tercera posición como importadora mundial durante el 2005 mientras que India quedó ubicada entre los veinte primeros. En vista de esta tendencia transitoria de fuerte demanda y de altos precios internacionales de los productos básicos, por las adquisiciones de China e India, seria recomendable para la región aumentar sus volúmenes de exportación aprovechando sus ventajas comparativas en los intercambios comerciales.

A pesar de ello, hay un tema al que se debe atender seriamente como es la inserción por parte de ALC en las cadenas globales de valor, aspecto fundamental para el futuro de la región. El acceso a dicha inserción se logrará en la medida que ALC oriente su producción hacia la complementariedad y especialización con dichos mercados en vez de buscar la competencia directa en sectores donde los países asiáticos cuentan con notorias ventajas de producción y también de calidad.

Por ello resulta necesario enfatizar la idea de participar en la complementariedad o especialización productiva en lugar de competir directamente con los productores de estas economías. A modo de ejemplo, como se señaló en el desarrollo del estudio, algunos sectores de México y Centroamérica dedicados a la producción de manufacturas (maquinaria industrial y eléctrica, productos electrónicos, equipos de transporte y textiles) se vieron desplazados por los productos chinos en el mercado de Estados Unidos incurriendo en grandes pérdidas.

En caso de que no se desarrolle este tipo de inserción, el principal frente de amenaza provendría de los mismos países latinoamericanos. Ello llevaría a perder una gran oportunidad para el pasaje hacia industrias de media y alta tecnología con fuerte sesgo exportador.

Además, es previsible que frente al reducido número de acuerdos de libre comercio existentes entre ALC y estos dos países en el largo plazo se registre una mayor participación de otras regiones geográficas más próximas, como el ASEAN, en el mercado Chino e Indio. Esto cuestionaría la situación actual de ALC como una de las principales zonas de abastecimiento de materias primas y de otros potenciales productos ya que eventualmente podría quedar relegada a una posición secundaria frente a este actor regional.

Finalmente, considerando la experiencia chilena con sus múltiples 
acuerdos preferenciales, los TLC como instrumentos de vinculación interregional constituyen una modalidad que podría eliminar las restricciones operantes en el sistema multilateral de negociaciones económicas, que perjudican los intereses de los países de la región. 


\section{Referencias Bibliográficas}

CASTILLA, Luis Miguel. China: oportunidades y desafíos para América Latina. Reporte de Economía y Desarrollo 2005. Caracas: Cooperación Andina de Fomento, dic. 2005. Disponible en: http://www.caf.com/attach/17/default/ LMCastilla(2).pdf. Acceso en: febrero 2007.

CESARÍN, Sergio. La doble oportunidad para América Latina y el Caribe: China e India en la Creación de Cadenas Globales de Valor. Buenos Aires: BID - INTAL/Instituto para la integración de América Latina y el Caribe, dic. 2005. Disponible en: www.iadb.org/intal/aplicaciones/uploads/ponencias/ Foro_REDEALAP_2005_16_Cesarin.pdf. Acceso en: febrero 2007.

CESARÍN, Sergio. La relación sino-latinoamericana, entre la práctica política y la investigación académica. Revista Nueva Sociedad, v. 203, n. 203, mayo./ jun. 2006.

COMISIÓN ECONÓMICA PARA AMÉRICA LATINA. CEPAL. China e India y sus relaciones comerciales con América Latina y el Caribe: oportunidades y desafíos. Panorama de la inserción internacional de América Latina y el Caribe 2005-2006. CEPAL, Santiago de Chile, sept. 2006. Disponible en: http://www.eclac.cl/publicaciones/xml/9/26619/ CapituloII.pdf. Acceso en: febrero 2007.

Aspectos estratégicos de la relación entre China y América Latina y el Caribe. Panorama de la inserción internacional de América Latina y el Caribe 2004. Tendencias 2005. CEPAL, Santiago de Chile, ago. 2005. Disponible en: http://www.eclac.cl/publicaciones/xml/5/22465/PAN_ E2004T05Cap5.pdf. Acceso en: febrero 2007.

Sobre la base de información oficial de los paises y datos del Fondo Monetario Internacional. Direction of Trade Statistics, 2006.

DIRECON - Dirección General de Relaciones Económicas Internacionales. (s/ f) [en línea]. Disponible en: http://www.direcon.cl/ documentos/India2/ antecedentes_generales_india.pdf. 
JETRO, Argentina. Análisis de la evolución del intercambio comercial entre América Latina y China. Jetro Buenos Aires oficina para Argentina, Paraguay y Uruguay. Gacetilla de Prensa, n. 5/05, Edición Especial, jul. 2005. Disponible en: http:/www.jetro.go.jp/argentina/prensa/gacetilla/ julio05_edesp.html. Acceso en: agosto 2007.

KRUGMAN, Paul R.; OBSTFELD, Maurice. Economía internacional: teoría y política. 5. ed. Madrid: Pearson Educación, 2001.

LÓPEZ-ALVEZ, Fernando. Sociedades sin destino. ¿América Latina tiene lo que se merece? Buenos Aires: Taurus, 2002.

OMC. Trade Profiles, 2006. Disponible en: http://stat.wto.org/CountryProfile/ WSDBCountryPFHome.aspx?Language=E. Acceso en: febrero 2007.

ROSALES, Osvaldo; KAWAYAMA, Mikio. América Latina y China e India: hacia una nueva alianza de comercio e inversión. Serie Comercio Internacional, Santiago de Chile, CEPAL, n. 81, enero. 2007.

WORLD BANK. Prospects for the global economy, country-specific historical data. The World Bank, Disponible en: http://web.worldbank. org/WBSITE/EXTERNAL/EXTDEC/EXTDECPROSPECTS/ EXTGBLPROSPECTSAPRIL/contentMDK:20413173 menuPK:65918 3 -pagePK:2470434 piPK:2470429 -theSitePK:659149,00.html. Acceso en: febrero 2007. 